\title{
O EU, O OUTRO E A ÉTICA DA ALTERIDADE: UM DIÁLOGO INTERTIEXTUAL ENTRE FERNANDO PESSOA E CAIO FERNANDO ABREU "
}

\author{
Anselmo Peres Alós**
}

\begin{abstract}
Resumo: Neste trabalbo, analisamos uma obra literária portuguesa (O Marinheiro, de Fernando Pessoa) e uma outra, brasileira ("O Marinbeiro", conto escrito por Caio Fernando Abreu), Para estabelecer relações inter-literárias entre estes dois textos, utilisamos o conceito de intertextualidade, desenvolvido por Julia Kristeva (1969). No final deste artigo, mostramos que, nos dois textos, bá a proposta de um projeto ético e, ao mesmo tempo, estético, presente na produçäo artística destes dois escritores.
\end{abstract}

"Tudo na vida é inacreditável, tanto na ilha do marinbeiro como neste mundo." (PESSOA, 1966: 56)

"Isso é tão estranbo que deve ser verdade." (PESSOA, 1966: 57)

"Não nos devieis ter contado essa bistória. Agora estranbo-me viva com mais borror." (PESSOA, 1966: 59)

"Abraça tua loucura antes que seja tarde demais." (ABREU, 1991:83)

- Recebido para publicação em março de 2002.

" Professor do Instituto de Letras da Universidade Federal do Rio Grande do Sul. 


\section{Introdução}

O objetivo deste ensaio é uma análise de cunho comparatista entre o drama estático do poeta português Fernando Pessoa intitulado O Marinbeiro ${ }^{1}$ (1913) e a narrativa homônima do contista brasileiro Caio Fernando Abreu, incluída no volume Triângúlo das Águas ${ }^{2}$ (1983). Os três subtítulos que dividem o trabalho ilustram o percurso que irei traçar em minha análise.

Cais é o lugar do qual o navio parte, rumo a novas terras. Ponto de partida por excelência, tal título reúne os pressupostos teóricos que funcionam como o cais dessa viagem intertextual que cruza o Atlântico e pretende mostrar de que forma o texto pessoano emerge na superfície textual da prosa de Caio Fernando Abreu. Entretanto, para rastrear o texto de Pessoa, fazse necessário "mergulhar" no texto de Abreu.

Naufrágio, destarte, é o segundo segmento deste escrito, que esquece a superfície textual de Abreu para mergulhar nos elementos criptografados "naufragados" sob esse mesmo texto: o poema dramático de Fernando Pessoa. Naufragando em Abreu, dele nos esquecemos por alguns momentos para averiguar o funcionamento do drama estático de Pessoa (vale ressaltar, estático como um navio encalhado no fundo do mar) para, em seguida, novamente emergir e avaliar de que forma o intertexto pessoano se faz presente na narrativa de Caio Fernando Abreu.

Resgate, por fim, é o título sob o qual se pretende trazer novamente à tona os elementos do intertexto pessoano dentro da narrativa de Abreu, estabelecendo algumas relações de ordem intertextual, atentando para o funcionamento dos elemen-

\footnotetext{
${ }^{1}$ PESSOA, Fernando. Poemas Dramáticos. Lisboa: Ática, 1966. v.1. ${ }^{2}$ ABREU, Caio Fernando. Triângulo das Águas. 2. ed. São Paulo: Siciliano, 1991.
} 
tos pessoanos dentro do novo texto, elaborado pelo escritor brasileiro. É a partir do intertexto pessoano que Abreu, lançando mão de técnicas como a citação e a alusão, elabora sua escrita, dando corpo ao marinheiro pessoano e avançando nas reflexões iniciadas pelo poeta português.

\section{CAIS}

\section{Pressupostos para uma leitura trans-atlântica}

Todo o texto, como já sublinhou Bakhtin, constitui-se através de múltiplas relações - relaçōes dialógicas - com outros textos. Todo texto é, na verdade, um intercâmbio discursivo e, sob sua superfície, entrecruza-se um emaranhado polifônico de vozes e consciências (SILVA, 1993: 624). Assim, lendo esta afirmação sob uma ótica marinha, poder-se-ia afirmar que todo o texto (mar) guarda em suas profundezas inúmeros intertextos que pesam em sua configuração final (navios naufragados).

Julia Kristeva, em seu Séméiotikè: recherches pour une sémanalyse (1969), retoma a noção bakhtiniana de dialogismo textual e desenvolve-a, forjando a noção de intertextualidade. Tornou-se clássico o fragmento da obra de Kristeva que define todo o texto como intertexto:

(...) tout texte se construit comme mosaïque de citations, tout texte est absortion et transformation d'un autre texte. À la place de la notion d'intersubjectivité s'installe celle de intertextualité, et le langage poétique se lit, au moins, comme double. (KRISTEVA, 1969: 146). ${ }^{3}$

\footnotetext{
3 "Todo o texto se constrói como um mosaico de citações, todo o texto é absorção e transformação de um outro texto. No lugar da noção de intersubjetividade, instala-se a de intertextualidade, e a linguagem poética é lida, ao menos, como dupla".
} 
Logo, a intertextualidade fica sendo definida como "a interação semiótica de um texto com outro(s) texto(s) (SILVA, 1993: 625)". Intertexto, por sua vez, é "o texto ou o corpus de textos com os quais um determinado texto mantém aquele tipo de interacção" (idem). Michael Riffaterre (1978) propõe que seja estabelecido, para definir a intertextualidade, que se leve em considéração uma relação estabelecida através de qualquer tipo de identidade estrutural (como se texto e intertexto se configurassem como variantes de uma mesma estrutura). Vítor Manuel de Aguiar e Silva discorda dessa postura de Riffaterre, lembrando que tal afirmação está ligada a uma "metafísica estruturalista" (SILVA, 1993: 626) que falseia - ao mesmo tempo em que não compreende - a dinâmica semiótica em toda a sua abrangência. Diz ele:

Ocorrem fenômenos de intertextualidade caracterizáveis em termos de identidade estrutural, mas ocorrem também múltiplos fenómenos de interacção textual que são refratários a tal caracterização. (...) a intertextualidade constitui um fenómeno da semiose cultural, actuante na história e no confronto das forças ideológicas e sociais, carecendo de convalidação científica a idéia de que os textos da cultura representam tão-só a modulação metamórfica de matrizes atemporais. (SILVA, 1993: 626).

O intertexto, por sua existência anterior e subterrânea ao texto, pode ser lido "debaixo", por assim dizer, da superfície do texto. Assim, há um texto outro, palimpséstico, oculto sob o texto, o que justifica a utilização de termos como subtexto e bipotexto no lugar da consagrada categoria intertextualidade (1978 e 1979). Antes, porém, de operacionalizar tais categorias, faz-se necessário um breve passeio pela intertexto pessoano, 
para que depois se possa retomá-lo no cortejo das duas obras.

\section{NAUFRÁGIO}

\section{$O$ intertexto estático em um quadro}

O Marinbeiro: drama estático em um quadro foi publicado pela primeira vez em 1913, na revista Orpheu I. É o único dos poemas dramáticos de Pessoa publicado em vida. Alguns apontamentos de Fernando Pessoa, incluídos na edição póstuma do primeiro volume de seus poemas dramáticos, dãonos uma dimensão do que venha a ser $O$ Marinbeiro. Antes de contemplarmos tais apontamentos, entretanto, cabem algumas considerações referentes à construção formal desta singular obra de Pessoa.

Este poema, ainda que assuma, por ocasião de sua construção formal, aspectos típicos do gênero dramático, continua sendo poesia antes de mais nada. As falas desta suposta "peça teatral" mantêm um ritmo cadenciado, poético por excelência. Além do mais, é notável a presença de metáforas como recurso de construção do drama. A respeito do caráter lírico da peça, o próprio Pessoa pronunciou-se, definindo-se a si próprio como um "poeta dramático":

O ponto central da minha personalidade como artista é que sou um poeta dramático; tenho continuamente, em tudo quanto escrevo; a exaltação íntima do poeta e a despersonalização do dramaturgo. (PESSOA, 1966: 25).

Ora, desde o trabalho dos formalistas russos que se sabe ser a poesia predominantemente metafórica, em oposição ao caráter metonímico (derivado da seqüencialidade e contigüi- 
dade) do texto prosaico. Assim, O Marinbeiro de Fernando Pessoa configura-se enquanto uma forma lírica híbrida, que lança mão de recursos dramáticos (em especial o de marcação de diálogos), mas nem por isso perde sua característica acentuadamente lírica (a presença da dominante metafórica em restrição à metonímica, assim como a alternância rítmica entre as falas das veladoras, das imagens suscitadas por essas falas e mesmo pelo aspecto rítmico do texto). Quando falo em ritmo, tenho em mente o conceito desenvolvido por O. Brik (1971), participante do Círculo Lingüístico de Moscou e do grupo de teóricos hoje conhecidos sob o termo formalistas russos:

Geralmente, chama-se ritmo a toda a alternância regular; e não nos interessa a natureza do que o alterna. O ritmo musical é a alternância dos sons no tempo. O ritmo poético é a alternância das sílabas no tempo. O ritmo coreográfico, a alternância dos movimentos no tempo. (BRIK, 1971: 131).

Em poucas palavras, o texto pessoano dá conta de um velório que se passa em um quarto de um castelo antigo, à noite. A ação (melhor talvez seria dizer a não-ação) se passa através de um diálogo hermético entre as três veladoras. Duas especulações costumam ser feitas a respeito desse dado. A primeira delas seria a de que cada uma das três veladoras seria um dos heterônimos de Pessoa, enquanto o cadáver no quarto seria o próprio Pessoa, sujeito empírico, que não estaria morto, mas dormindo, hipnotizado, possuído ou qualquer coisa que o valha, enquanto seus heterônimos produzem o que poderíamos chamar de a palavra poética. Assim, a dicotomia mundo real/ mundo onírico, tão presente no poema, daria conta de uma experiência de cisão vivenciada pelo próprio Pessoa por ocasião 
da criação de seus heterônimos. A figura do marinheiro, destarte, seria Fernando Pessoa heterônimo (não o sujeito empírico, mas o heterônimo que assina o drama estático em um quadro). Nesta hipótese, a primeira veladora seria Alberto Caeiro (o árcade), a segunda seria Ricardo Reis (o homem racional) e a terceira seria Álvaro de Campos (o modernista inconformado). Entretanto, ainda que essa suposição seja tentadora, não encontra respaldo textual no poema pessoano, visto que as vozes dessas três veladoras são difusas demais para que se torne possível uma suposta "apreensão" de uma essência identitária individual.

O que mais interessa para a presente aproximação do texto de Fernando Pessoa e Caio Fernando Abreu é a figura do marinheiro. As três veladoras conversam, mas seu diálogo é difuso, desencontrado. Um dos temas principais desse diálogo é a memória. É o que nos diz a Primeira Veladora quando diz "sempre é belo falar do passado" (PESSOA, 1966: 38). Mais do que o passado ou a memória, é a necessidade da construção de um passado que justifique o presente o leitmotiv desse drama estático.

A Segunda Veladora, entre estas reflexóes sobre a memória, lembra-se de um sonho que tivera, e conta-o para suas companheiras. Neste sonho, ela conta a história de um marinheiro naufragado, que consegue chegar a uma ilha deserta. Como esse náufrago sofria muito todas as vezes em que se lembrava de sua terra natal, pôs-se a imaginar uma nova pátria, "uma outra espécie de país com outras espécies de paisagens, e outra gente, e outro feitio de passarem pelas ruas e de se debruçarem pelas janelas" (PESSOA, 1966: 49). Durante muito tempo o marinheiro realizou este exercício para livrar-se da dor provocada pelas lembranças de sua pátria. Até que, depois de anos, "um dia, que chovera muito, e o horizonte estava mais 
incerto, o marinheiro cansou-se de sonhar... Quis então recordar a sua pátria verdadeira..." (PESSOA, 1966: 52). Mas não conseguiu. Havia esquecido completamente sua terra, e não podia nem ao menos sonhar um outro passado, a não ser aquele que, por anos a fio, para livrar-se da melancolia, havia sonhado.

É a partir deste trecho que a alteridade se torna um conceito-chave para a compreensão do poema-drama. Após terminar o relato de seu sonho, a Segunda Veladora afirma: "Nenhum sonho acaba... Sei eu ao certo se o não continuo sonhando, se não o sonho sem saber, se o sonhá-lo não é esta coisa vaga a que eu chamo vida?..."(PESSOA, 1966: 54). É através do sonho que a Segunda Veladora busca o contato com o Outro: o Outro, entretanto, é um Outro sonhado, dado que o onírico é o único espaço onde não reduzimos o Outro a uma essência para fins cognitivos. A apreensão do Outro só é possivel a partir do reconhecimento da irredutibilidade da diferença; em suma, para não reduzir o Outro, é necessário pensar através de uma lógica outra, é preciso assumir o locus de enunciação do outro.

Através da metáfora onírica é que Pessoa exercita o reconhecimento do Outro sem reduzi-lo. E a ambivalência do texto da qual fala Kristeva (le langage poétique se lit, au moins, comme double), está presente no texto pessoano, a partir do momento que o autor fecha seu drama estático com uma marcação (um tipo de discurso metadiegético, que dá informações para a montagem do espetáculo dramático):

Um galo canta. A luz, como que sùbitamente, aumenta. As três veladoras quedam-se silenciosas e sem olharem umas para as outras.

Não muito longe, por uma estrada, um vago carro geme e chia. (PESSOA, 1966: 62). 
Ao terminar seu drama estático com essa informação (escrita inclusive com recuo de parágrafo e em corpo menor, o que caracteriza um outro tipo de discurso, externo à diegese textual), Pessoa não apenas exerce formalmente essa busca pelo Outro (uma Outra voz suplementar, que realiza o desfecho do texto sugerindo que as três veladoras estão também sendo sonhadas, como o marinheiro que sonharam), mas cristaliza a ambigüidade ao deixar em suspenso a reação do leitor, que fica livre para julgar essa afirmação (a de que as veladoras estão sendo sonhadas) como diegética ou extradiegética. Tal como afirma a Segunda Veladora em meio a uma discussão sobre a real existência ou não do sonhado marinheiro:

...Vede, vede, é dia já... Vede o dia... Fazei tudo por reparardes só no dia, no dia real, ali fora... Vede-o, Vedeo... Ele consola.... Não penseis, não olheis para o que pensais... Vedeo-o a vir, o dia... Ele brilha como ouro numa terra de prata. As leves nuvens arredondam-se à medida que se coloram... Se nada existisse, minhas irmãs? Se tudo fosse, de qualquer modo, absolutamente coisa nenhuma? (PESSOA, 1966: 57).

\section{RESGATE}

\section{A interação do Eu-Abreu com o Outro-Pessoa}

É com a citação anterior que Caio Fernando Abreu abre seu $O$ Marinbeiro. A narrativa desenvolve-se tomando como cenário um pequeno sobrado, habitado por um narrador autodiegético sem nome que foi, pouco a pouco, perdendo seu contato com o mundo. Esse personagem vai desenvolvendo uma série de excêntricos hábitos, como o de pintar pelo lado de dentro com tintas coloridas as vidraças do sobrado. E é justa- 
mente aí que encontramos o primeiro tropo comum entre as duas obras: o quarto de castelo antigo, com apenas uma janela quadrada, em torno da qual se juntam as veladoras, é análogo ao pequeno sobrado da obra de Abreu.

"Descobri faz algum tempo que as mãos se opõem à cabeça, e quando você movimenta aquelas, esta pode parar. (...) Ocupo-me, desde então, fazendo coisas que depois disponho pelos cantos" (ABREU, 1990: 72). A busca frenética desse narrador por fazer "parar a cabeça" - solucionada através de uma compulsão por atividades artesanais - visa ao mesmo resultado que leva a Segunda Veladora a contar o seu sonho com o marinheiro: esvaziar a mente dos maus pensamentos. Enquanto a veladora pode "parar o tempo", por assim dizer, através da narração do seu sonho (um dos traços que vem a caracterizar a obra de Pessoa como um drama estático em um quadro é a quebra metadiegética introduzida pela narração da Segunda Veladora), a suspensão da passagem do tempo entre um evento e outro (na obra de Abreu) se dá por metonímia, na medida em que este faz parar o fluxo de seus pensamentos através de atividades manuais. Por associação metonímica, onde o fluxo mental estanca, o tempo está suspenso.

Entretanto, esse "estancar o passar do tempo" através de atividades manuais (na obra de Abreu) mostra um resultado falacioso, pois a passagem do tempo só fica suspensa a partir do momento em que uma das vozes do universo diegético assume o controle da instância narrativa e narra uma outra história, criando assim uma dimensão metaléptica (mise-en-abîme) que, pelo deslocamento que causa no plano diegético, sugere a passagem do tempo. E, nos dois textos, é através dessa cisão metaléptica que a figura do marinheiro é incluída. Antes, porém, de se fazer a investigação das significações suscitadas pelo marinheiro, é interessante fazer uma investigação do campo semânti- 
co que envolve essa constelação simbólica (nas palavras de Gilbert Durand [1996]), formada por símbolos como a água, a ilha e o navio. Dado que o marinheiro se configura como um símbolo também aquático, a decifração desses outros símbolos dessa mesma constelação vão auxiliar na compreensão de outras significações implícitas que o marinheiro, enquanto símbolo, vai refratar nos dois textos.

As águas, segundo Durand, possuem um duplo aspecto. Nas águas diurnas, o símbolo aquático aponta para a emotividade, para a sensibilidade e para a feminilidade. Por outro lado, as águas noturnas carregam sentidos nictomórficos de circularidade e repetição (o arquétipo da Roda), assim como um sentido de perigo obscuro, de adversidade oculta. No tarot, por exemplo, ainda segundo Durand, a figura que cristaliza esse aspecto noturno das águas é $A$ Lua, uma carta na qual, sob as águas de um lago obscurecidas pela nebulosa luminosidade do luar, um tenebroso escorpião mostra suas pinças, pronto para atacar. Tanto em Abreu quanto em Pessoa, é o aspecto nictomórfico das águas - presente tal como se mostra na significação cristalizada sobre a carta da Lua - que irá prevalecer.

A ilha, por sua vez, remete a um lugar paradisíaco, refúgio no qual o passar do tempo deixa de ser uma ameaça. Uma cristalização típica do arquétipo da ilha é a Terra do Nunca, da obra de James Barrie (1972), onde é possível ser criança por toda a eternidade. Por fim, o navio é o veículo que faz a ligação entre dois mundos, por navegar sobre o mar, veículo transcendental por excelência que liga o mundo terreno a um outro mundo, espiritual. Logo, se o navio é um veículo transcendental, também o é aquele que o habita, que o conduz. Se o navio é um ponto de ligação entre dois mundos, o marinheiro faz as vezes de intermediário entre o mundano e o espiritual. Tal cristalização simbólica está também presente na lenda de 
Caronte, o barqueiro que levava as almas dos Mortos até o Tártaro, através do rio de águas fétidas e pestilentas.

Destarte, o marinheiro funciona, tanto na narrativa brasileira como no drama estático português, como uma espécie de elo entre dois mundos. Como já foi visto, na obra pessoana o marinheiro dá vazão a uma discussão que tem como tema a cisão entre sonho e realidade, sendo que o heterônimo Pessoa levanta a possibilidade, através de um recurso metaléptico (as observações sobre o cenário da peça, apresentadas sob a forma de marcações $)^{5}$ de estarmos sendo sonhados, em um outro lugar. Na obra de Caio Fernando Abreu, o marinheiro é o responsável por uma espécie de rito de passagem, no qual o narrador autodiegético é levado pelo marinheiro de um ponto de desequilíbrio (o isolamento causado pelas perdas do passado) a um novo estágio (a redescoberta da existência para além do auto-isolamento), como se pode ver nos três parágrafos finais da narrativa:

Daqui a pouco vai amanhecer. Há um vago cheiro de mar solto nas ruas.

Hesito um pouco na esquina. Antes de me pôr a caminho, abro devagar e completamente os braços para depois fechá-los arredondados, tocando suavemente as pontas dos dedos de uma das mãos nas pontas dos dedos da outra. Como se faz para abraçar além do ar da manhã. Mas não há nada entre meus braços além do ar da manhã. Suspiro, sorrio, desfaço o abraço.

s Importante ressaltar que nem sempre as marcaçōes figuram como um recurso metaléptico nas peças teatrais. Isso ocorre somente quando há a transposição de um nível narrativo (diegético) para um outro maior; que o compreende (metadiegético). 
Então, com as mãos vazias, finalmente começo a navegar. (ABREU, 1991: 106)

De qualquer forma, uma mera identificação do intertexto pessoano em Caio Fernando Abreu, ou a exegese que vasculha os sentidos simbólicos de certos elementos textuais não configuram, em si mesmos, a chave para a compreensão da intertextualidade entre Pessoa e Abreu. É necessário não apenas investigar a migração de elementos pessoanos para a obra de Abreu, mas também analisar como tais elementos são apropriados, de que forma interagem com os outros elementos do texto para, enfim averiguar qual a motivação ideológica que está por trás dessa apropriação textual. Como já foi observado por Silva:

Por um lado, a intertextualidade representa a força, a autoridade e o prestígio da memória do sistema, da tradição literária: imita-se o texto modelar, cita-se o texto canónico, reitera-se o permanente, cultiva-se, em suma, a beleza e a sabedoria sub specie aeternitatis ou, pelo menos, sub specie continuitatis. Por outro lado, porém, a intertextualidade pode funcionar como um meio de desqualificar, de contestar e destruir a tradição literária, o código literário vigente (...). (SILVA, 1993: 632).

É obvio que, em nenhum momento, Caio Fernando Abreu teve a intenção de contestar ou desqualificar o drama estático de Pessoa. Muito pelo contrário, a utilização do discurso do outro por Abreu funciona daquela forma descrita por Bakhtin em Marxismo e Filosofia da Linguagem (1997), quando o lingüista russo diz que:

(...) o discurso de outrem constitui mais do que o tema do discurso; ele pode entrar no discurso e na sua cons- 
trução sintática, por assim dizer, 'em pessoa', como uma unidade integral de construção. Assim, o discurso citado conserva sua autonomia estrutural e semântica sem nem por isso alterar a trama lingüística do contexto que o integrou.(...)

O discurso citado é visto pelo falante como a enunciação de uma outra pessoa, completamente independente na origem, dotada de uma construção completa, e situada fora do contexto narrativo (BAKHTIN, 1997: 144).

Desta forma, a utilização do discurso citado por Abreu, ao contrário de reduzir o texto pessoano à condição de "țema" de sua narrativa, faz justamente o inverso: ao mesmo tempo em que mantém a autonomia do texto pessoano (pois, no momento em que cita, preserva a integridade e a irredutibilidade do outro intertextual), encaixa a voz do outro em seu próprio texto. Assim, o encontro com o outro, que, via de regra, está condicionado pela episteme que reduz o outro à condição de objeto enquanto privilegia o mesmo como sujeito cognoscente, é subvertido. A narrativa de Abreu retoma a alegoria pessoana do marinheiro para desenvolver todo um projeto ético, onde a relação com o outro não está sujeitada a nenhum esquema hierárquico. Tanto Abreu quanto Pessoa colocam-se, em relação ao outro, ao lado de, e não em uma posição superior e privilegiada. É a partir do encontro com o outro que o mesmo se reconhece, sem, entretanto, reduzir o outro à condição de objeto cognoscível.

Para finalizar, retomo um fragmento de Silva:

Semântica e pragmaticamente, aliás, toda a intertextualidade, mesmo quando aparenta circunscrever-se a uma simples actividade lúdica, nunca é ideologicamente inocente ou asséptica, reenviando sempre, embora de 
um modo dissimulado, oblíquo e até oculto, a uma cosmovisão, a um universo simbólico em que se acredita ou que se denega. (SILVA, 1997: 633).

Assim, torna-se clara a filiação ideológica de Abreu em seu jogo intertextual com o drama pessoano: a proposta de uma nova ética no que diz respeito à alteridade, na qual o sujeito coloca-se lado a lado com o outro, sem reducionismos, sem essencialismos. No lugar da relação sujeito-objeto, uma relação sujeito-sujeito, subordinada pela égide da alteridade e da diferença. Dada a fusão do horizonte do eu com o horizonte do outro, justifica-se, pois, os tons oníricos de ambos os textos, pois ao pensar por uma lógica outra, a própria construção formal do texto não pode mais estar presa à linearidade do pensamento do Mesmo. É necessária uma escrita fractal, nebulosa, que refrate o outro enquanto Outro, tornando possível o encontro, mas de uma forma ética que o respeite enquanto um Outro sujeito e não o reduza aos esquemas lógicoformais do Mesmo.

Résumé: Dans ce travail, nous analysons un ouvrage littéraire portugais (O Marinheiro, de Fernando Pessoa) et un conte brésilien ("O Marinbeiro", de Caio Fernando Abreu). Pour étudier les relations inter-littéraires entre ces deux textes, nous utilisons le concept d'intertextualité, developpé par Julia Kristeva (1969). À la fin de cet article, nous montrons que, dans les deux textes, il y a la proposition d'un projet étbique et esthétique, présent dans la production artistique des deux écrivains. 


\section{Referências bibliográficas}

ABREU, Caio Fernando. Triângulo das Águas. 2. ed. rev. pelo autor. São Paulo: Siciliano, 1991.

BAKHTIN, Mikhail. Marxismo e Filosofia da Linguagem. 8. ed. Trad. Michel Lahud e Yara Frateschi Vieira. São Paulo: Huicitec, 1997.

BARRIE, James. Peter Pan. Trad. Paulo Mendes Campos. Rio de Janeiro: Edições de Ouro, 1972.

BRIK, O. et al. Teoria da Literatura: Formalistas Russos. Trad. Ana Maria Ribeiro, Maria Aparecida Pereira, Regina L. Zilberman e Antônio C. Hohlfeld. Revisão: Rebeca P. da Silva. Org., Apresentação e Apềndice de Dionísio de Oliveira Toledo. Prefácio de Boris Schnaiderman. Porto Alegre: Globo, 1971.

DURAND, Gilbert. As Estruturas Antropológicas do Imaginário. São Paulo: Martins Fontes, 1996.

KRISTEVA, Julia. Séméiotikè: recherches pour une sémanalyse. Paris: Éd. du Seuil, 1969.

PESSOA, Fernando. Poemas Dramáticos. Lisboa: Ática, 1966. v.1. Semiotics of Poetry. Bloomington; London: Indiana University Press, 1978.

RIFFATERRE, M. La Production du Texte. Paris: Éd. du Seuil, 1979.

SILVA, Vítor Manuel de Aguiar e. Teoria da Literatura. 8. ed. v.1. Coimbra: Almedina, 1993. 